\section{Reflections of a Phoenix}

\author{
P.W. Atkins
}

International Reviews in Physical Chemistry. Editors A.D. Buckingham et al. 3/yr. (Butterworths.) $£ 12.50$ UK, $\$ 31.25$ North America (personal); $£ 45$ UK, $\$ 112.50$ North America (institutional).

International Reviews in Physical Chemistry is the Phoenix which has arisen from the ashes of the MTP International Review of Science: Physical Chemistry (a series which expired after its second coming in 1975-76). The initial aim of the new series was to be the same as review journals everywhere: to cater for more or less everyone, from the involved research worker to the passing generalist. As such it was in direct competition with several other publications with readily confusable titles, like the Annual Review of Physical Chemistry and Annual Reports (General and Physical Chemistry).

The articles that have appeared so far have ranged widely in length and degree of specialization, although the recent trend, as judged from the small sample yet published, has shifted in favour of length and specialization, and consequently has rendered the reviews only marginally appropriate to the general reader. For the specialist, however, I suspect that the shift is valuable. Instead of coming down firmly between the two stools of general and special readerships, which other publications serve perfectly adequately, the editors are beginning to offer us a journal capable of lengthy reflection on a sequence of specialized fields such as the study of transient species with vacuum ultraviolet photoelectron spectroscopy and rotational fine structure in dynamic photophysical processes. For that there has been a need, and if this journal retains its present format, and is not scuttled by commercial unviability, then it could turn into a substantial and useful contributor to the research scene.

Apart from the review papers the journal offers book reviews, but only infrequently: this service should be extended. As to format and appearance, a half-blind careless reader might think he had picked up a copy of that earlier Phoenix, the Transactions of the Faraday Society.

The editors appear to be successful in attracting authoritative contributors: the of Oxford. publication times are indefinite but appear tolerable. So, in summary: not bad; settling down; useful to specialists; authoritative; moderately expensive; worth watching.

P.W. Atkins is a Fellow of Lincoln College and Lecturer in Physical Chemistry at the University

\section{By numbers}

\section{W. Graham Richards}

Theochem. Editors I.G. Csizmadia et al. $20 / \mathrm{yr}$ in 5 vols. (Elsevier Scientific.) Dfl.950. Journal of Computational Chemistry. Editors N.L. Allinger and P. von R. Schleyer. 4/yr. (Wiley.) \$85 US, $\$ 101$ elsewhere.

OVER the dead bodies of some traditional chemists, particularly those who devise undergraduate practical courses, a new subdiscipline is growing. This is computational chemistry. It even has its own division within the American Chemical Society. The subject is distinct from theoretical chemistry, the end products being neither theories nor equations but numbers.

The computer is used as a tool rather like a spectrometer. Some applications are computer simulations; others are calculations of molecular energies either from purely empirical potentials or from quantum mechanical calculations, be they semiempirical or of the $a b$ initio variety. Relatively few authors apply the computed molecular wavefunctions to calculate molecular properties other than energies.

At the time of its appearance I greeted Theochem (a new journal created by subdividing the Journal of Molecular Structure) with some suspicion and declined to be a member of the editorial board on grounds of lack of time. Despite this I have since used the journal both as author and as reader. Clearly the journal has overcome the prejudice of researchers and is now firmly established as a main-line vehicle for publication of calculations of molecular structure.

The range of the Journal of Computational Chemistry (JCC) is wider. It encompasses not only molecular structure calculations but also statistical mechanics, Monte Carlo calculations and computerassisted organic synthesis. Since its inception in 1980, JCC has established itself as the market leader in this broad area of computational chemistry and has become an essential journal in some in- dustrial contexts as well as in academe.

Both new journals are well produced and seem to have grown beyond the fledgling stage, if only on the evidence that the delay between receipt of a paper and its appearance in print is about a year; this is typical of an established organ. There is no doubt that both will survive and grow fatter as more and more work is produced in the area in which they serve.

That more work will appear is also beyond doubt. Computational chemistry is inextricably linked to development in computer hardware where no obvious threshold in advancement is in sight. Cheaper and more powerful minicomputers, more capable micros with longer word lengths, and the new breed of supercomputers with vector and array processors will all combine to generate more papers for both publications. Their market and readership will indubitably grow, and the editors will be able to maintain high standards.

In one important respect, however, both of these journals and indeed the publishing world in general are not geared to satisfy the needs of the computational chemist. Alongside the advances in computational power has grown a more important hardware availability, that of computer graphics. With the use of colour, the computational chemist can make his work assimilable to the experimentalist and even to boards of directors in scientificallybased companies. Ideally, any journal serving computational chemists should be able to publish graphical output in full colour. Cost is the limitation. To my knowledge a body of fascinating work is being presented at conferences but is never seen by readers of the scientific literature.

The first journal which can overcome this problem will be very attractive to computational chemists. In the meantime Theochem and JCC will satisfy most other demands.

Graham Richards is a Lecturer in Physical Chemistry at the University of Oxford.

\section{Catalytic work}

\section{David J.H. Smith}

Applied Catalysis. Editor-in-chief B. Delmon. $12 / \mathrm{yr}$ in 4 vols. (Elsevier Scientific.) Dfl.820.

THERE has been a rapid growth of activity in catalysis, fuelled by industry's need to conserve energy and husband resources, and it was inevitable that a new journal would be launched to cope with the increase in available material. I'm not sure I know what "applied catalysis" is, but the intended scope of this recent arrival on the 